\title{
Potential Coatings for Aircraft Brakes Application. Part I: Thermal Spray Coatings
}

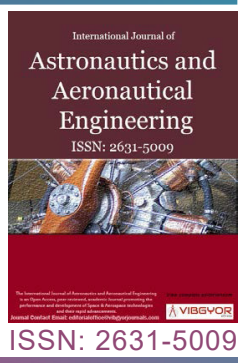

\section{Granata ${ }^{1}$, G Gautier di Confiengo ${ }^{2}$, D Scamardella ${ }^{3}$ and F Bellucci ${ }^{*}$}

${ }^{1}$ CRdC Tecnologie Scarl, Via Nuova Agnano 11, Italy

${ }^{2}$ CNR STEMS, strada delle Cacce 73, Italy

${ }^{3}$ TSS Thermal Spray Service, Via Solfegna Cantoni, Italy

\begin{abstract}
Over the last years, in the context of the electric aircraft technology trend, the development of electric brakes in replacing hydraulic systems has gained great interest due to its several potential benefits. Currently, materials for brakes for aircrafts range from the low-cost sintered friction pad/liner material vs sintered rotor disc material to the high cost carbon fiber material vs carbon fiber material. The subject of this work was developed in the framework of a European project (E-BRAKE) aimed at developing, manufacturing, testing, and qualifying an innovative Electro-Mechanical Braking actuation system for small aircraft application. This paper addresses the potential use of thermal spray technologies to produce a thin film of friction material onto low-carbon steel substrate to allow its use as potential composite material for the stators and rotors of brake units.

In this research Stellite grade 1 (Cobalt-Chromium alloy), Colmonoy 6 (Nickel-Chromium alloy), Tungsten Carbide (Metal Ceramic composite) and Chromium Oxide (Oxide ceramic) coatings were deposited with two different thermal spray technologies, respectively the High Velocity Oxygen Fuel (HVOF) and the Atmospheric Plasma Spraying (APS), for the purpose of creating high friction and wear resistance composite coatings onto low-carbon steel substrate. Tribological properties (friction coefficient and wear rate), thermal conductivity, and diffusivity as well as metallographic structures and adhesion to the low-carbon steel substrate were evaluated to assess the potential use of the coatings as brake surface materials. The tribological and adhesion properties were evaluated by using a pin-on-disk high temperature Tribometer at $450{ }^{\circ} \mathrm{C}$ and a scratch test, respectively. The metallographic structures of the coatings were analysed with an Optical Microscope NIKON Eclipse 2150. Results obtained in this investigation show that all coatings exhibit high friction coefficients and low wear rates compared to the low-carbon steel substrate, good adhesion and a dense and solid microstructure. Furthermore, the Tungsten Carbide coating shows thermal conductivity and diffusivity higher than that of the low-carbon steel substrate. Findings reported in this study suggest that the thermal-sprayed Tungsten Carbide coating shows better properties than the other investigated coatings and, therefore, can be considered as a potential coating for brake materials. In fact, this coating shows dense and solid microstructures with a very low level of porosity (less than 1\%), absence of un-melted particles, a very low presence of oxides and no cracks. In addition, the Tungsten Carbide exhibits: (i) The best adhesion to the low-carbon steel substrate with a very high critical load of detachment (around $65 \mathrm{~N}$ ), (ii) Very high friction coefficient $(0.84)$, and (iii) Very low wear rate. In the wear tests carried out on the Tungsten Carbide coatings, it was impossible to evaluate the wear tracks because the surface of the coating was only flattened. Lastly, Tungsten Carbide presents superior thermal properties compared to that exhibited by the low-carbon steel substrate.
\end{abstract}

\footnotetext{
*Corresponding author: F Bellucci, CRdC Tecnologie Scarl, Via Nuova Agnano 11, 80125 Napoli, Italy Accepted: October 29, 2021; Published: October 31, 2021

Copyright: (C) 2021 LGranata M, et al. This is an open-access article distributed under the terms of the Creative Commons Attribution License, which permits unrestricted use, distribution, and reproduction in any medium, provided the original author and source are credited.

Granata M, et al. Int J Astronaut Aeronautical Eng 2021, 6:056
}

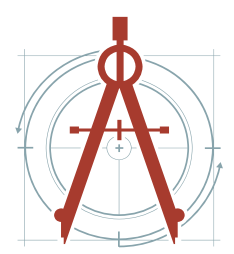




\section{Keywords}

Thermal spraying, High velocity oxygen fuel, Atmospheric plasma spraying, Thermal application, Composite coatings, Wear-resistance coatings, Friction material coatings

\section{Introduction}

The rapid development of additive manufacturing technologies has improved the choice of materials in various industrial sectors, specifically relating to friction materials for brakes application in the aeronautical sector. Brakes are responsible for conversion of excess kinetic energy into thermal energy by increasing the wheel rolling friction, thus reducing the vehicle speed. Braking systems employ this principle for slowing down or stopping the vehicles.

A typical multi-disk aircraft brake is schematically shown in Figure 1. As can be seen in this figure, the brake consists of series of discs; The stators, which are stationary units connected to the wheel axle or leg, and the rotors, which form the rotating part [1], connected to the wheel. Under the action of hydraulic pressure, these series of discs get compressed, forcing the wheel to slow down due to friction. The discs are typically provided with slots for better heat dissipation at high temperature. During the braking action, the brake is activated by the hydraulic system pressure, which compresses the heat stack. In this way, the rotors and the stators are squeezed together by hydraulic pistons and the brake produces torque by virtue of friction

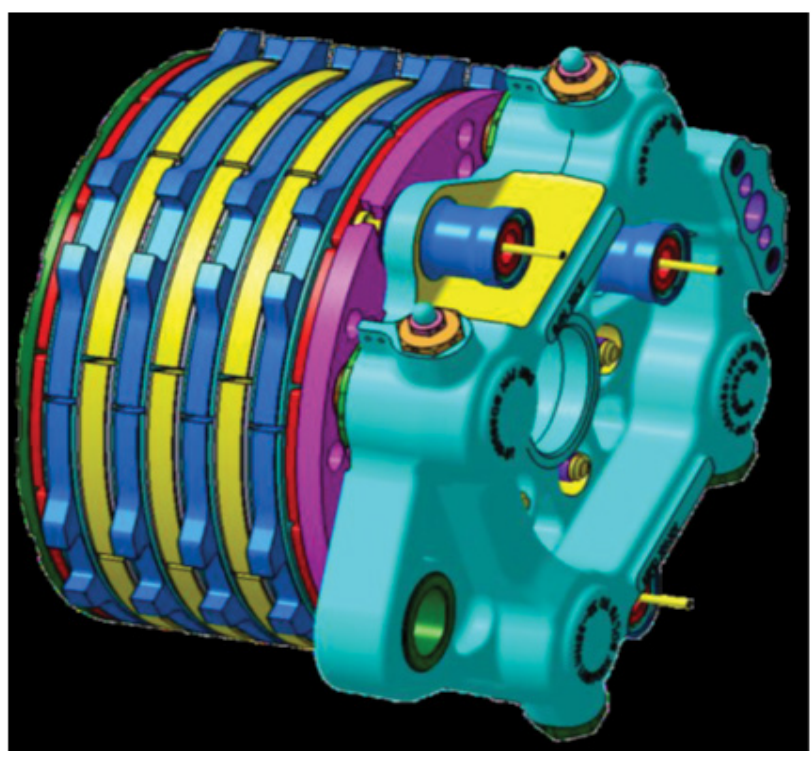

Figure 1: Aircraft brake system. forces generated at the rubbing interface between the rotors and the stators.

Rotor and stator can be in different materials. The first material and the most common for small aircraft is steel. It can be used carbon steel as well as stainless steel. This type of material has been extensively studied over the years and because of its high mechanical properties that lead to an improvement in the braking action with a high energy. It also resists at high mechanical stress and present a low production cost. On the other hand, steel materials present different disadvantages such as a low resistance to corrosion mechanism that accelerated at high temperature which entail a periodic maintenance operation [2].

After an extensive study of the latest literature works the main materials currently used to make aircraft brakes are steel, Ceramic Matrix Composite, Metal-Matrix Composite (MMC) and Carbon Composites.

Shangwu Fan, et al. [3] present a brief review on the state of the art of advanced ceramic matrix composites materials for aircraft brake application, focusing the attention on manufacturing process, properties and wear mechanisms of $\mathrm{C} / \mathrm{SiC}$ materials, as well as progress and future of the aircraft brake materials. The same Shangwu Fan, et al., in another work [4], analysed the microstructural characteristics and tribological properties of carbon/silicon carbide composite materials (C) $\mathrm{SiC}$ ) composed of layers of non-woven fiber cloth, short fiber web, and needle fibers, finding excellent braking performance and wear resistance.

Regarding to Metal-Matrix Composites (MCMs), $M$ Maleque and $U$ Abdullahi [5] analysed the braking performance of carbon nanotube aluminium matrix materials (CNT-Al) a nano-composite materials with the aim to find an alternative lightweight and cheaper materials for aircraft brake disc application, concluding that CNT-Al represents an excellent candidate material for brake disc application. In the paper, the advantages and disadvantages between aluminium metal matrix composite and other materials as well as the advantages of powder 
metallurgy with other processes are also reported.

This type of material represents a real innovation in technical-scientific field. Brakes made in carbon fiber materials are used almost only in automotive competitions and high-performance aircrafts, as they require high temperatures to generate braking force. In 1988 S. Awasthi, et al. [6] underlined the importance of reducing weight on the braking performance. In the paper braking system with different types of carbon composite materials $(C / C)$, their processing and properties are reported.

The choice of carbon fibers is due to the properties of these materials whose friction coefficient increases with increasing temperature that means it brakes better when it is hot [7]. In the latter case braking takes place by "fusion" of the pads to the disc whose junction pieces are literally torn off during braking. Carbon brakes are made with carbon in the form of fibers (not graphitized) and immersed in a graphite matrix. Furthermore, this material is very light, obtaining excellent specific properties. On the other hand, carbon brakes present a very high production and design costs as well as a low static friction coefficient that makes parking performance not optimal.

To reduce the costs related to brake production -without significantly altering the braking performance- the innovative solution proposed is to use rotor and stator discs made in steel, both equipped with a thin coating (e.g. $0.5 \mathrm{~mm}$ ) of a suitable friction material. In this way the main brake material is steel covered with a noble coating.

The ideal coating material for the best braking action should exhibit high tribological properties, specifically high friction coefficient and high wear resistance, high thermal properties, in particularhigh thermal conductivity and diffusivity, good adhesion to the substrate, a compact microstructures and low porosity inside the coating. In addition to the requirements reported above the coating should be very light to reduce the total weight of the vehicle, and the design and production should be low cost.

The coatings reported in this scientific work are made by using two different Thermal Spray technologies, namely High Velocity Oxygen Fuel (HVOF) and Atmospheric Plasma Spraying (APS). The first technology was used to create coatings in Stellite, Colmonoy and Tungsten Carbide, while the APS spraying technology was used to create a coating with a CoNiCrAlY alloy bond coat and a Chromium Oxide layer topcoat.

Thermal spraying, also commonly known as metal spraying, is a surface coating process where a wide range of metals and ceramics can be sprayed onto the surface of another material. The most of these processes are based on giving kinetic and thermal energy to powders to achieve, through a partial melting an acceleration of it, the better adhesion on a substrate.

The HVOF thermal spray process is characterized by very high gas and particle velocities, followed by a low gas temperature, as compared to plasma spray processes [8]. Typically, a common combustion of Kerosene and pure oxygen produces a Mach 2 jet that melts or partially melts the powder and projects them on the substrate giving the highest bond value between coating and substrate. These techniques combine high velocity powder particles with low temperature to build up a dense and tightly adherent coating with low oxidation and residual stress $[9,10]$. Therefore, hard friction material can be applied on many different substrates such as steels, plastic materials, titanium, copper, aluminium, and other different metallic alloys [10]. The application of ceramic coatings obtained via HVOF improves the coated substrate properties, such as corrosion resistance, wear-resistance, hardness or combinations of these to extend product life, to increase performance and to reduce production time and costs. The coating quality, such as physical and mechanical properties of HVOF sprayed coatings are strongly influenced by its structure that depends on the process parameters such as the fuel/oxygen ratio flow rate, nozzle geometry, spray distance and powder size distribution [11].

Despite the purpose is the same as for other thermal spray processes, the philosophy at the base of the APS technology is completely different, and surely is the most sophisticated and fascinating one between them. In fact, gas such as $\mathrm{Ar}, \mathrm{H}_{2}, \mathrm{~N}_{2^{\prime}}$ $\mathrm{He}$, are flowed through an electric arc that drives the gas to become plasma. The result is to produce heat and pressure waves that, investing the powder, transfer kinetic and thermal energy useful to project it onto the substrate.

With these technologies it is possible to use a wide range of powders for the realization of 
Table 1: HVOF process parameters for the deposition of satellite, Colmonoy 6 and WC coatings.

\begin{tabular}{|l|l|l|l|l|}
\hline Sample & Gun & Nozzle length [mm] & $\begin{array}{l}\text { Flowrate Oxygen } \\
{[\mathbf{l} / \mathbf{m i n}]}\end{array}$ & Flowrate Kerosene [l/h] \\
\hline Stellite & K2 & 150 & 900 & 26 \\
\hline Tungsten Carbide & K2 & 150 & 870 & 24 \\
\hline Colmonoy 6 & K2 & 150 & 800 & 20 \\
\hline
\end{tabular}

Table 2: APS process parameters for the deposition of bond coat CoNiCrAlY coatings.

\begin{tabular}{|l|l|l|l|l|l|l|}
\hline Sample & Gun & $\begin{array}{l}\varnothing \text { Nozzle } \\
{[\mathbf{m m}]}\end{array}$ & $\begin{array}{l}\text { Spray distance } \\
{[\mathbf{m m}]}\end{array}$ & $\begin{array}{l}\text { Flowrate Argon } \\
{[\mathbf{l} / \mathbf{m i n}]}\end{array}$ & $\begin{array}{l}\text { Florate Hydrogen } \\
{[\mathbf{l} / \mathbf{m i n}]}\end{array}$ & $\begin{array}{l}\text { Current Intensity } \\
{[\text { [A] }}\end{array}$ \\
\hline $\begin{array}{l}\text { Chromium Oxide } \\
\text { top-coat }\end{array}$ & F4 & 6 & 140 & 91 & 90 & 630 \\
\hline $\begin{array}{l}\text { CoNiCrAlY bond- } \\
\text { coat }\end{array}$ & F4 & 6 & 130 & 55 & 9 & 600 \\
\hline
\end{tabular}

Table 3: Coatings thickness.

\begin{tabular}{|l|l|}
\hline Coating & Thickness $(\mathbf{m m})$ \\
\hline Stellite & 0.4 \\
\hline Tungsten Carbide & 0.4 \\
\hline Colmonoy 6 & 0.4 \\
\hline Chromium Oxide top-coat & 0.375 \\
\hline CoNiCrAlY bond-coat & 0.125 \\
\hline
\end{tabular}

different coatings and the choice depends on the properties that the coating must exhibit. The mains are WC (tungsten carbide), $\mathrm{CrC}$ (chromium carbide), $\mathrm{Cr}_{2} \mathrm{O}_{3}$ (chromium oxide), Nickel-based alloys, Cobalt-based alloys.

Finally, results obtained in this investigation by using thermal spraying technologies were compared with literature data [12] using the HighPressure Cold Spray Technology (HP-CS).

\section{Experimental Procedures}

\section{Materials and technologies}

Low-carbon steel squared samples (4 $\mathrm{mm}$ in thickness and $19 \mathrm{~mm} \times 19 \mathrm{~mm}$ in surface) were used as the substrate. These samples were covered with Stellite, Colmonoy and Tungsten Carbide respectively, with the High Velocity Oxygen Fuel (HVOF) technology, while APS technology was used to cover with CoNiCrAlY bond coat and Chromium Oxide topcoat. The HVOF and APS spraying parameters are reported in Table 1 and Table 2, respectively, while coating thickness are reported in Table 3.
Table 4: Composition of Colmonoy 6 alloy powder.

\begin{tabular}{|l|l|}
\hline Element & Composition (\%) \\
\hline Nickel (Ni) & Balance \\
\hline Chromium (Cr) & 15 \\
\hline Boron (B) & 3 \\
\hline Silicon (Si) & 4.5 \\
\hline Iron (Fe) & 4.5 \\
\hline Carbon (C) & 0.7 \\
\hline
\end{tabular}

Commercially obtained feedstock powders of Stellite grade 1 were provided by Commersald [13]. Stellite grade 1 alloys are a range of cobalt-based alloys composed of chromium and tungsten with a small percent of carbon [14]. Chromium content gives resistance to oxidation and hardens by solid solution and by precipitation of carbides. Tungsten, mainly, gives hardening for solid solution.

Colmonoy 6 feedstock powders were provided by LSN Diffusion (nickel-based alloy powder, grade $\mathrm{N}-580$ ) [15]. The composition of Colmonoy 6 powder is reported in Table 4 and Table 5. As reported in this paper, this alloy provides sufficient adhesive and abrasive wear resistance, owing to the presence of high chromium and boron content. Colmonoy 6 alloys have also high hardness due to the presence of chromium carbides and chromium borides content in the substance.

Lincotek (also known under the name Artec) provided Tungsten Carbide powder [16]. Among different types of thermal spray coatings, the Tungsten Carbide ones is widely used when abrasion, sliding, fretting, and erosion resistance 
Table 5: Test Condition.

\begin{tabular}{|l|l|l|l|l|l|}
\hline & Speed $(\mathbf{c m} / \mathbf{s})$ & Load $(\mathbf{N})$ & Temperature $\left({ }^{\circ} \mathbf{C}\right)$ & Length (laps) & Counterpart \\
\hline Test 1 & 20 & 10 & 450 & 50000 & Alumina ball \\
\hline Test 2 & 20 & 10 & 450 & 25000 & Alumina ball \\
\hline Test 3 & 10 & 5 & 450 & 25000 & Alumina ball \\
\hline
\end{tabular}

are required. The reason is that the hard Tungsten Carbide coatings exhibit high hardness and wear resistance.

Praxair provided CoNiCrAlY and $\mathrm{Cr}_{2} \mathrm{O}_{3}$ powders [17]. CoNiCrAlY is a metal alloy belonged to the MCrAlY category. To further enhance resistance to corrosion and oxidation, MCrAlX-based overlay coatings $(\mathrm{M}=\mathrm{Ni}$ and $\mathrm{Co}, \mathrm{X}=\mathrm{Y})$ are deposited to low-carbon steel surface. Compared to diffusion coatings, overlay coatings are less dependent on the composition of the substrate, but also more expensive, since they must be carried out by air or vacuum plasma spraying (APS/VPS). The MCrAIY is the latest generation of bond coat and does not strongly interact with the substrate. MCrAlY coatings are secondary aluminium oxide formers. This means that the coatings form a layer of chromium oxide (chromia), and a secondary aluminium oxide (alumina) layer underneath. The chromia provides oxidation and hot-corrosion resistance whereas the alumina controls oxidation mechanisms by limiting oxide growth by selfpassivating. Finally, the yttrium enhances the oxide adherence to the substrate and limits the growth of grain boundaries [18].

\section{Parameters investigated and analysis method}

Once created the different coatings the parameters investigated were Tribological Properties (Friction Coefficients and Wear Rate), Structural Properties (Adhesion of coatings on the low-carbon steel substrate, Metallographic Structures and Coating Hardness) and Thermal Properties (Thermal Conductivity and Thermal Diffusivity).

Adhesion test and metallographic structure: The microhardness and the metallographic properties of HVOF and APS coatings were investigated with the following equipment:

- Coatings Microhardness

o Durometer: Off. Galileo

o Model: ERGOTEST COMP 25ARS o Calibration Every test

o High Range HR15N scale

An average value of 5 measurements was taken.

- Coatings Metallographic structure

o Cutting of test specimen: IMPETECH Europe -Abrasive cutter-

o Embedding of test specimen: Embedding made in air at $35^{\circ} \mathrm{C}$

o Lapping of test specimen: IMPETECH Europe -Digital polisher-

- Metallographic examination: Optical Microscope NIKON Eclipse 2150

Adhesion tests of Thermal Spray coatings were conducted in form of scratch test (Revetest Scratch Tester) using a Rockwell $C$ diamond stylus $200 \mu \mathrm{m}$. Test were conducted under a normal load continuously increasing from $1 \mathrm{~N}$ to $70 \mathrm{~N}$, with a loading rate of $100 \mathrm{~N} / \mathrm{min}$ and $10 \mathrm{~mm} / \mathrm{min}$ of speed rate. Scratch test consists of pressing a diamond stylus onto the surface of the coating, applying either a constant or an increasing load, while the sample is moved at a constant speed. Coating detachment at the critical load is a quantification of the adhesion. During the test, the indenter begins to scratch with a very low initial load. As the load increases, it gradually penetrates the coating. As the depth of penetration increases, the stress of the material also increases. Once reached the critical load, the material collapses and cracks form and the coating may peel off. Two critical loads are evaluated, namely (i) Lc1 load at which the formation of cracks occur, and (ii) Lc2 the load at which a total detachment of the coating from the substrate is observed.

Tribological tests: The tribological tests were carried out with a High Temperature (HT) Tribometer at the temperature of $450{ }^{\circ} \mathrm{C}$. The pinon-disk tribometer, shown in Figure 2, consists in a flat, pin, or sphere, attached to a stiff elastic arm that is weighted down onto a test sample 


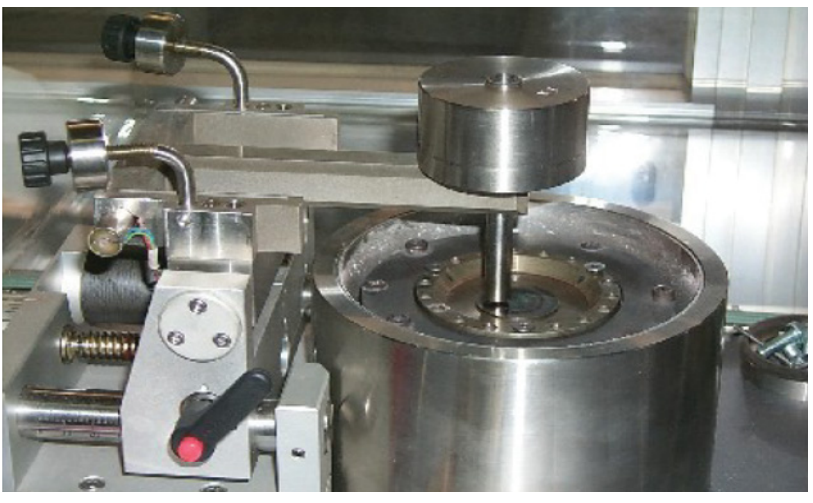

Figure 2: Pin-on-disk tribometer.

with a known weight. The sample is rotated at a selected speed. The counterpart uses to evaluate tribological properties is an alumina ball with a diameter of 6 millimetres. In order to avoid possible third body phenomena due to high wear derived from the ball, alumina ballas counterpart has been chosen, because is an abrasive material with high temperature resistance. In this way, eliminating the possible wear ball, it would have been more understandable to discriminate between the different coatings.

The elastic arm ensures a nearly fixed contact point and a stable position in the friction track formed by the pin on the sample. The kinetic friction coefficient is determined during the test by measuring the deflection of the elastic arm.

Variations in the coefficient of friction and wear rates of the coting materials analysed as a function of temperature, as well as their stability, will be the subject of future works.

This work aims to highlight the possibility of using additive manufacturing technologies (mainly thermal spray technologies) to create high performance friction coatings as a potential use for aircraft brakes.

In order to find the best test friction coefficient conditions, three different tests were conducted on low-carbon steel samples, under the conditions shown below (Table 5):

Wear volume is measured by analysing the wear tracks at the end of the test using a contact profilometer. Samples wear behaviour were compared using k wear:

$$
K \text { wear }=\frac{\text { Wear volume }\left(\mathrm{mm}^{3}\right)}{\mathrm{Nm}}
$$

Where wear volume is the lost volume, $\mathrm{N}$ is the test load (Newton) and $\mathrm{m}$ is the test length.

Test 3 showed the lowest volume loss and a more homogenous wear track. For this reason, this condition was selected as reference test. Due to high wear resistance of Tungsten Carbide coating, a test at $10 \mathrm{~N}$ was conducted, while laps, temperature and counter face remained the same. Only one test was done at $10 \mathrm{~N}$ because also at $10 \mathrm{~N}$ wear track was difficult to evaluate.

Thermal properties: The thermal conductivity of a material is a measure of its ability to conduct heat. It is commonly denoted by letter $\mathrm{k}$ or $\lambda$ and it is an intrinsic property of the material. Heat transfer occurs at a lower rate in materials of low thermal conductivity than in materials of high thermal conductivity. For instance, metals typically have high thermal conductivity and are very efficient at conducting heat, while the opposite is true for insulating materials like polymers. Correspondingly, materials of high thermal conductivity are widely used in heat sink applications, and materials of low thermal conductivity are used as thermal insulation.

A further characterizing the thermal properties of a material are the thermal diffusivity coefficient usually denoted as $\alpha$ or D defined as follow [19].

$$
\alpha=\frac{k}{\rho c_{p}}
$$

Where $k$ is thermal conductivity $(W /(m \cdot K)), \rho$ is density $\left(\mathrm{Kg} / \mathrm{m}^{3}\right)$ and $\mathrm{c}_{\mathrm{p}}$ is specific heat capacity $(\mathrm{KJ} /$ $(\mathrm{Kg} \cdot \mathrm{K}))$.

As clearly shown by its definition, the thermal diffusivity is an intrinsic characteristic of the material. Like all diffusion coefficients it is measured in $\mathrm{m}^{2} / \mathrm{s}$ in the International System. It is particularly useful for describing the propagation of a thermal field in non-stationary conditions. High values of alfa imply lower time to reach the steady state.

\section{Result and Discussion}

\section{Metallographic structure and adhesion of thermal sprayed coatings}

Figure 3 and Figure 4 show the optical microscope morphologies of coatings obtained with the HVOF and APS technologies, respectively. These sprayed specimens have a light grey colour on the entire coated surface, while the Plasma sprayed ones 

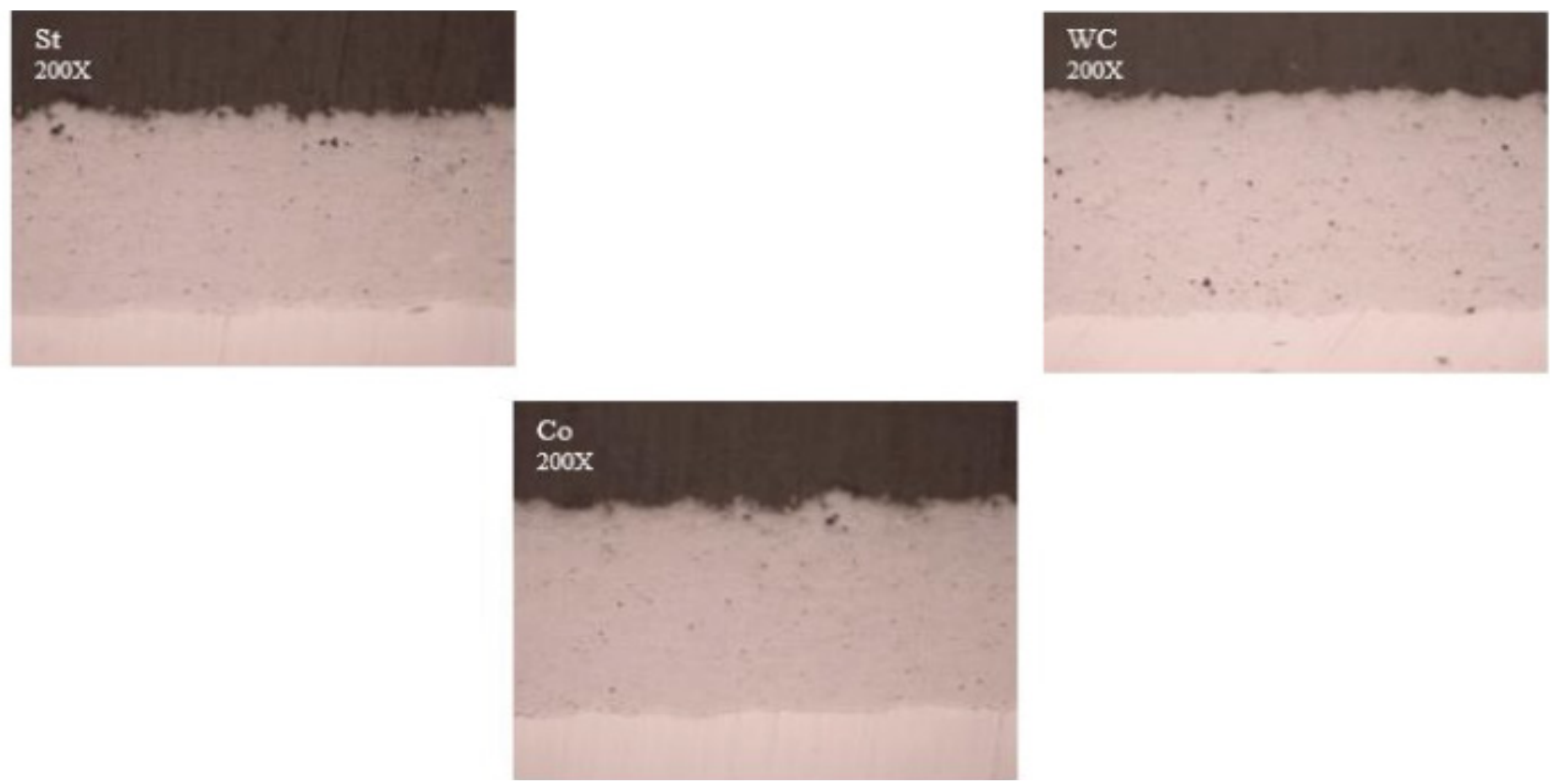

Figure 3: Metallographic examination of Stellite 1, Colmonoy 6 and tungsten carbide.
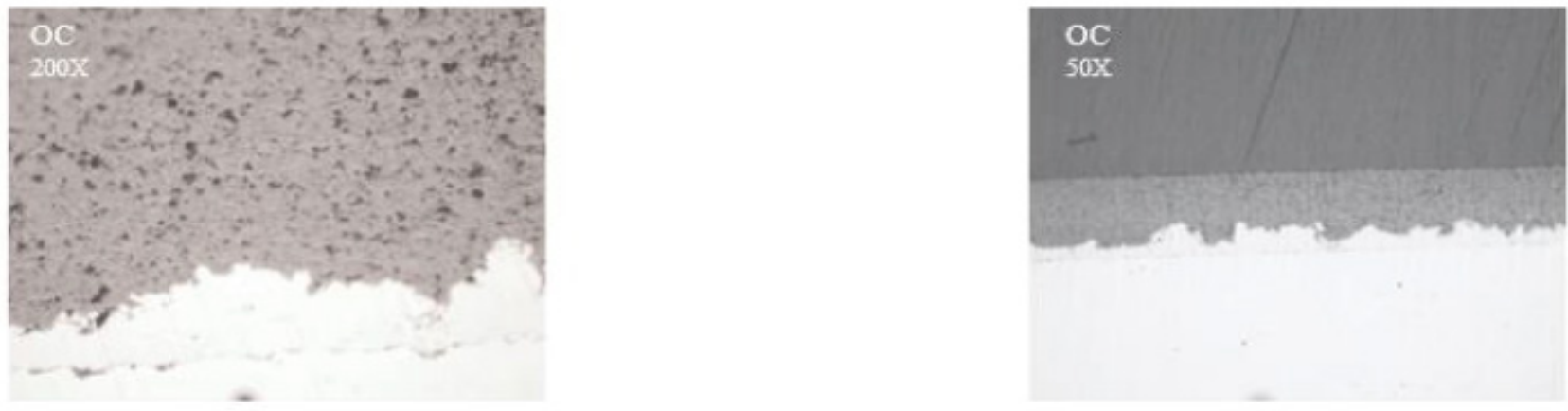

Figure 4: Metallographic examination of CoNiCrAlY bond coat and chromium oxide topcoat.

Table 6: HVOF coatings metallographic examination data.

\begin{tabular}{|l|l|l|l|l|l|l|l|}
\hline Sample & Porosity & $\begin{array}{l}\text { Unmelted } \\
\text { particle }\end{array}$ & $\begin{array}{l}\text { Interface } \\
\text { contamination }\end{array}$ & Oxides & $\begin{array}{l}\text { Interface } \\
\text { Separation }\end{array}$ & Cracks & $\begin{array}{l}\text { Rockwell } \\
\text { Hardness } \\
\text { (HR15 N scale) }\end{array}$ \\
\hline Stellite grade 1 & $<1 \%$ & Absent & $<0.5 \%$ & $<1 \%$ & No separation & No Cracks & $90.83 \pm 0.75$ \\
\hline $\begin{array}{l}\text { Tungsten } \\
\text { Carbide }\end{array}$ & $<1 \%$ & Absent & $<0.5 \%$ & $<1 \%$ & No separation & No Cracks & $93.16 \pm 1.17$ \\
\hline Colmonoy 6 & $<1 \%$ & Absent & $<0.5 \%$ & $<1 \%$ & No separation & No Cracks & $89 \pm 1.09$ \\
\hline
\end{tabular}

exhibit a dark grey colour on the entire coated surface. As reported in Table 6, the HVOF spray coatings present a very low level of porosity (less than $1 \%)$, absence of un-melted particles, a very low present of oxides and no cracks. No interface separation and contamination between the different materials present into the coatings were observed.

As reported in Table 7, the APS spray coatings 
Table 7: APS coatings Metallographic examination data.

\begin{tabular}{|l|l|l|l|l|l|l|}
\hline Sample & Porosity & $\begin{array}{l}\text { Interface } \\
\text { contamination }\end{array}$ & Delamination & $\begin{array}{l}\text { Interface } \\
\text { Separation }\end{array}$ & Cracks & $\begin{array}{l}\text { Rockwell } \\
\text { Hardness } \\
\text { (HR15 N scale) }\end{array}$ \\
\hline $\begin{array}{l}\text { Chromium } \\
\text { Oxide TopCoat }\end{array}$ & $4 \%$ & $<35 \%$ & $\begin{array}{l}\text { No } \\
\text { Delamination }\end{array}$ & No separation & No Cracks & \\
\hline $\begin{array}{l}\text { CoNiCrAlY } \\
\text { Bond Coat }\end{array}$ & $2 \%$ & $<35 \%$ & $\begin{array}{l}\text { No } \\
\text { Delamination }\end{array}$ & No separation & No Cracks & $96 \pm 0.63$ \\
\hline
\end{tabular}
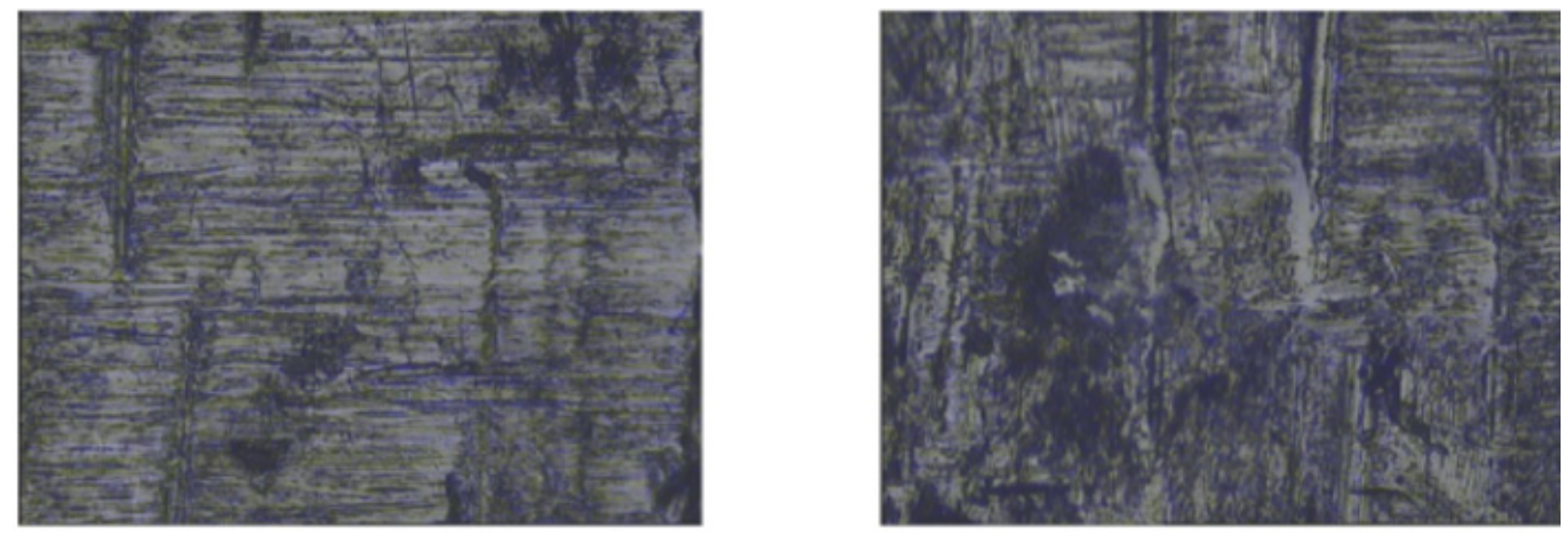

Figure 5: Scratch test results of satellite coatings.

also present a very low level of porosity (less than $4 \%)$, without crack and delamination, no interface separation between the different material present into the coatings and an interface contamination less than $35 \%$.

No significant differences were observed between the different coatings that have a hardness between 89 to 96 . Higher results were obtained for Chromium Oxide. In Table 7 it is reported the same hardness data result for CoNiCrAlY bond coat and Chromium Oxide topcoat. This is because the hardness of the coating mainly depends on the Chromium Oxide, while the function of the bond coat alloy is essential to favour the adhesion between the ceramic and the low-carbon steel substrate. For this reason, the hardness tests ware not carried out on the individual coating materials, but on the coating composed of CoNiCrAlY bond coat layer and Chromium Oxide topcoat layer.

These results were compared with those reported in the Ref. 12 . The SEM morphologies of the $\ln 625, \ln 625-\mathrm{Cr}_{2} \mathrm{O}_{3}$ and $\ln 625-\mathrm{Cr}_{2} \mathrm{O}_{3}$-Ag coatings appear to be fully dense without cracks or voids.
Adherence between the substrate and the In625 coating seems to be excellent, as the interface can hardly be distinguished. The distribution of the $\mathrm{Cr}_{2} \mathrm{O}_{3}$ particles is uniform and there are no obvious regions of porosity between the spray layers. The In625- $\mathrm{Cr}_{2} \mathrm{O}_{3}-\mathrm{Ag}$ composite coating EDS mapping shows that the deformed particles on the top surface are impacted and embedded into the previously deposited layers. By using cold spraying technology, the significantly higher impact velocity compared with the tradition thermal spay process enables most of the particles to penetrate deeply into the coating surface.

In addition to the microstructures, the adhesion between coating and low-carbon steel substrate was also evaluated. The Scratch test result of Stellite 1, Tungsten Carbide and Colmonoy 6 were reported in Figure 5, Figure 6 and Figure 7, while in Figure 8 are shown the results of CoNiCrAlY bondcoat were reported. The images on the left show the cracked surface obtained once reached the first critical load (LC1). The images on the right, instead, show the surface of sample once the coating has 

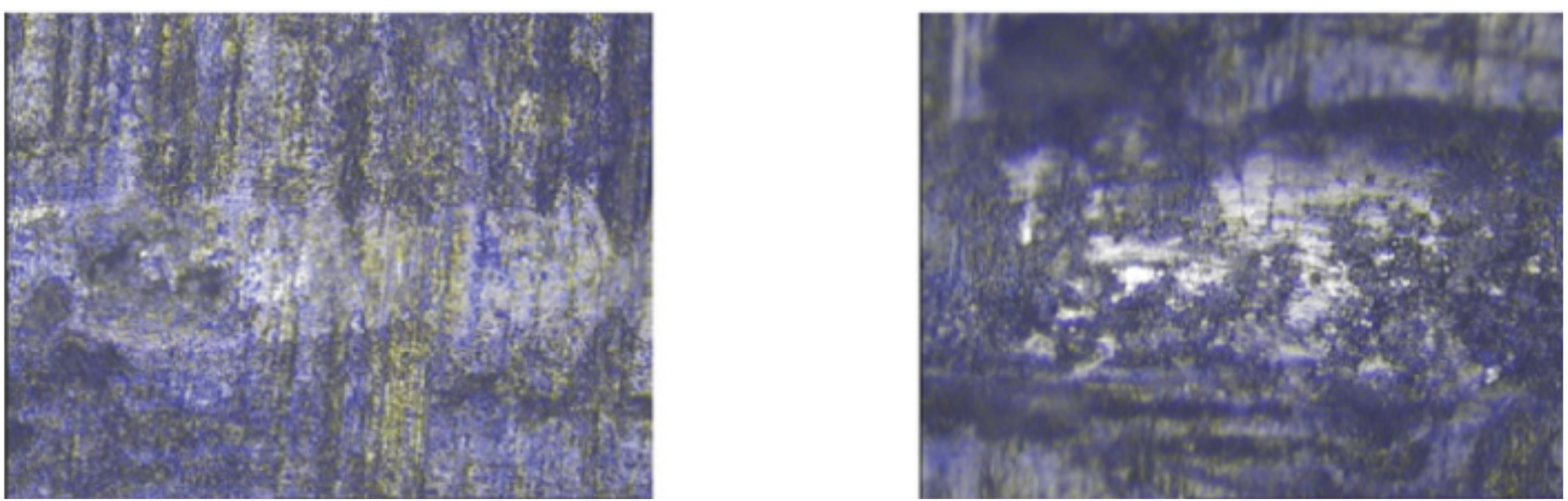

Figure 6: Scratch test results of tungsten carbide coatings.
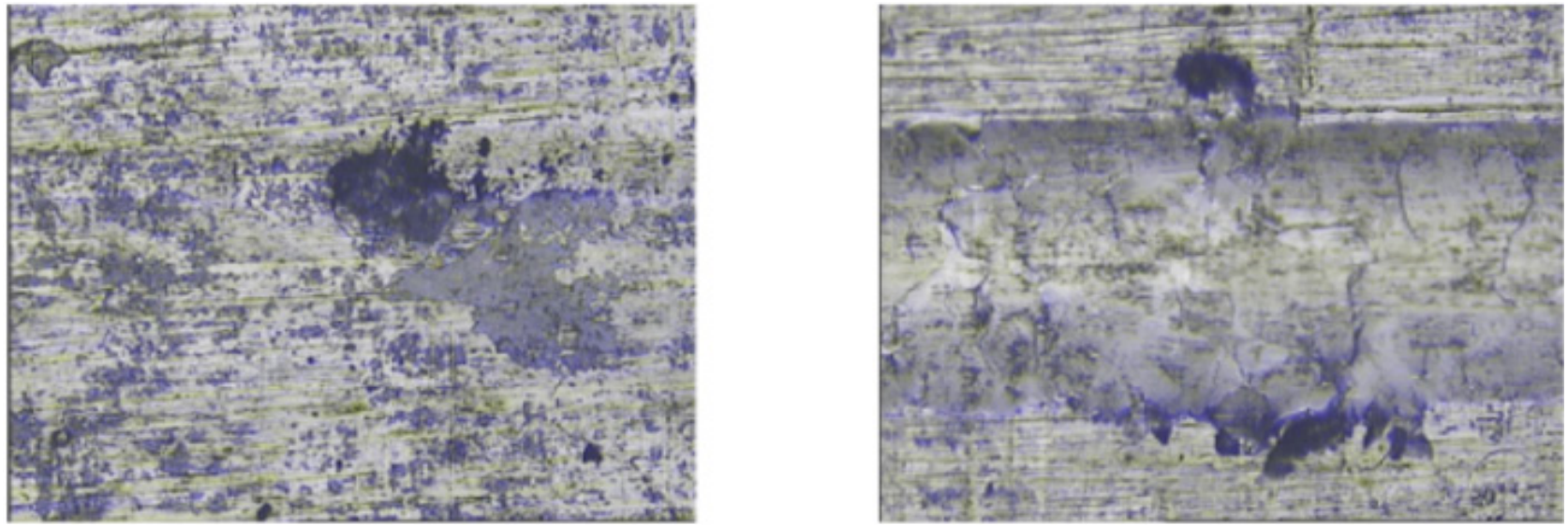

Figure 7: Scratch test results of colmonoy 6 coatings.
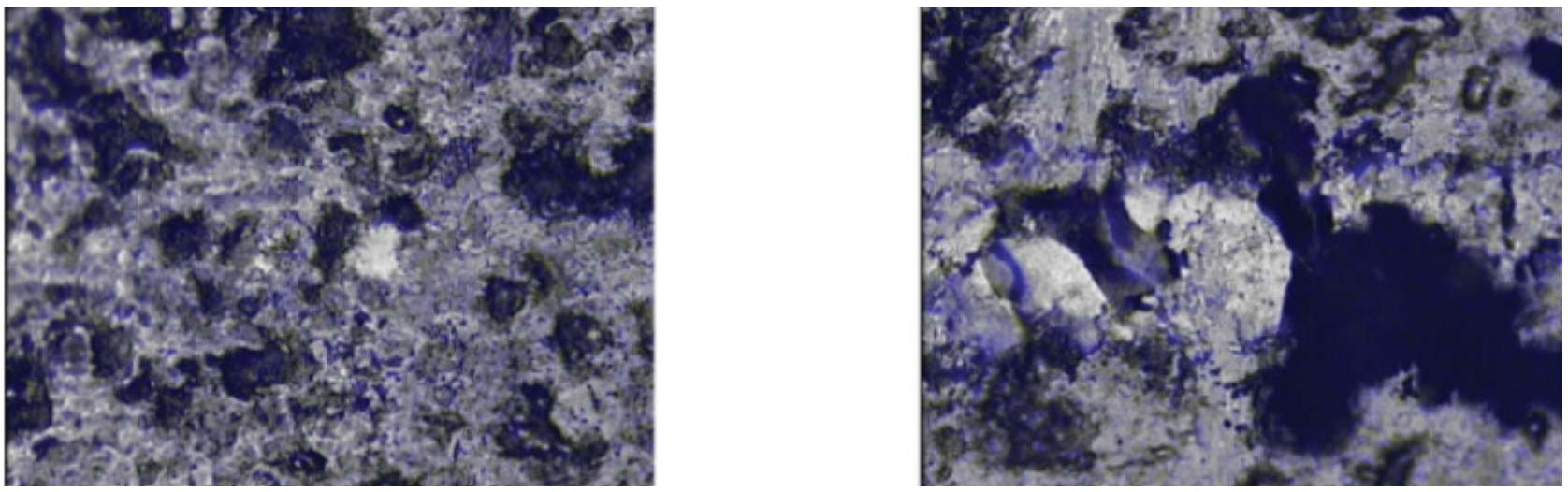

Figure 8: Scratch test results of CoNiCrAlY bond coat and chromium oxide topcoat coatings.

detached after reached the second critical load (LC2).

All the coatings showed a similar damage. Indeed, cracks inside scratch channel together with spalling phenomena are present in all tested coatings. At the beginning of scratch track, the width and shape of the failure show non-uniformities that can be due to the surface roughness and to the brittle fracture of the coatings.

In Figure 9, it is reported the comparison of the two different critical loads of the coatings produced. As shown in this figure, Tungsten Carbide 


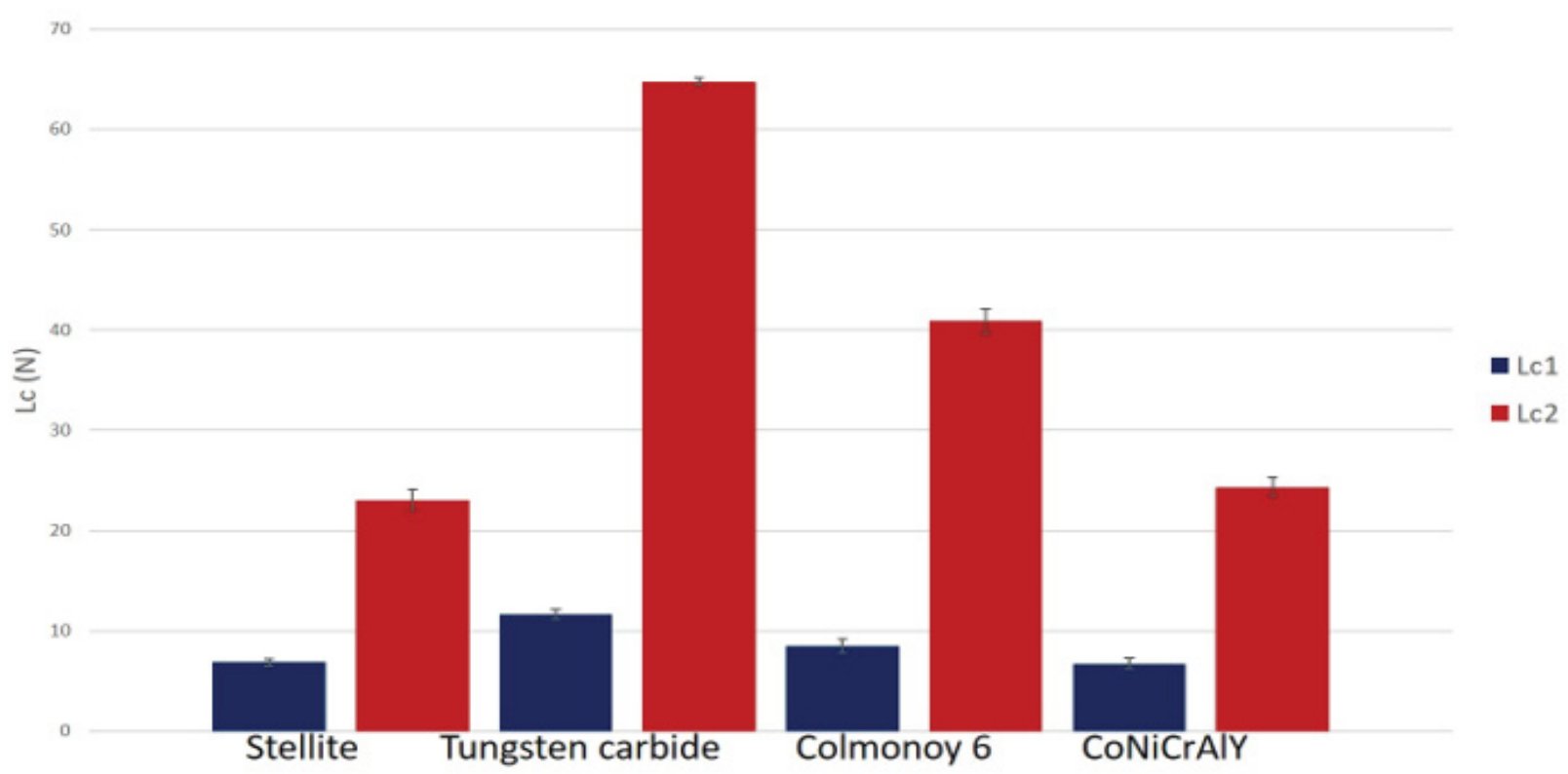

Figure 9: Critical load of cracks begin (blue) and detached (red).

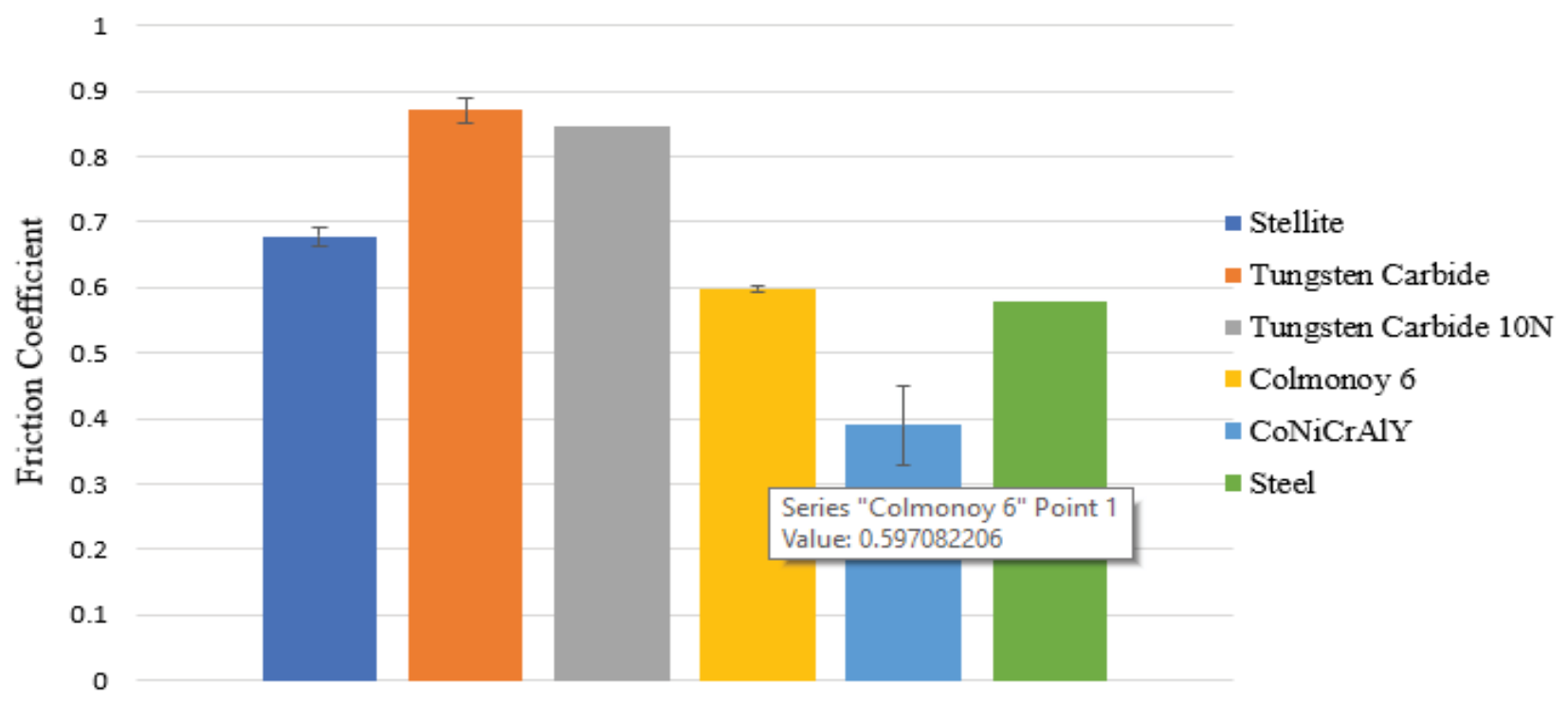

Figure 10: Friction coefficient histograms of thermal spray coatings.

coating present better adhesion to low-carbon steel substrate. The results show a critical load at the beginning of cracks at about $10 \mathrm{~N}$ and a critical load of separation at $65 \mathrm{~N}$.

\section{Friction and wear tests}

Friction and wear test were carried out on lowcarbon steel samples to obtain a comparative starting baseline.

The wear mark surface analysis of alumina ball has been measured at the end of each tribological test. Alumina ball wear imprints diameters, for all the tribological test, were in the range between 0.8-0.85 mm. Because there weren't significant differences between the imprints results were not reported.

Figure 10 shows the friction coefficients histograms of each coatings exanimated, while their values are reported in Table 8. Test conducted on the same coating showed similar value except 
Table 8: Friction coefficient average.

\begin{tabular}{|l|l|}
\hline & Friction Coefficient Average \\
\hline Stellite 1 & 0.68 \\
\hline Tungsten Carbide at 5N & 0.87 \\
\hline Tungsten Carbide at 10N & 0.84 \\
\hline Colmonoy 6 & 0.60 \\
\hline CoNiCrAlY bond coat and Chromium Oxide top coat (OC) & 0.39 \\
\hline
\end{tabular}

\section{Friction Coefficient}

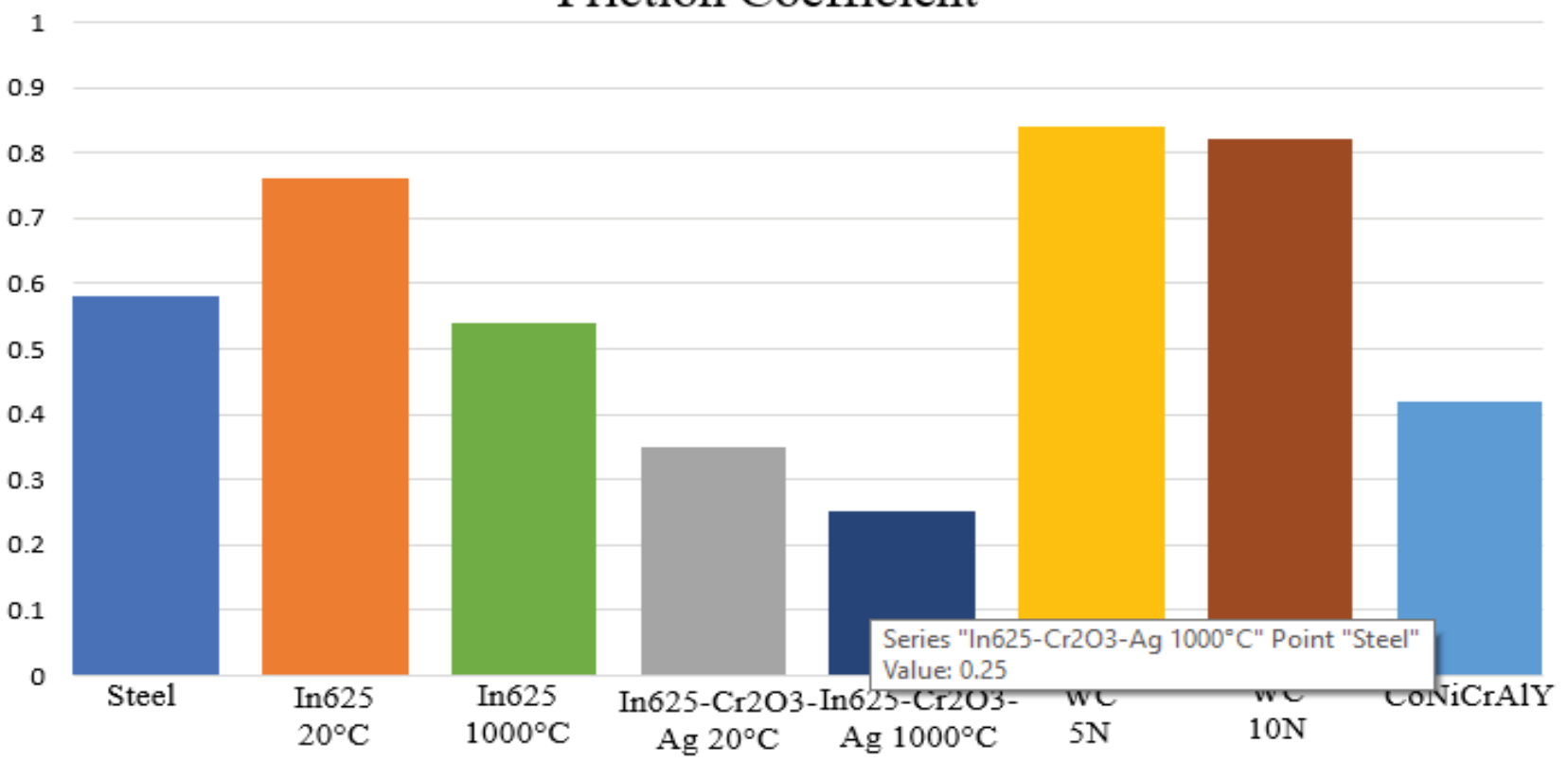

Figure 11: Friction coefficient of different materials.

for $\mathrm{Cr}_{2} \mathrm{O}_{3}$. Tungsten Carbide test made at different load exhibited the same friction coefficient evolution. Higher fluctuation was observed for both Colmonoy 6 samples. By comparing the average friction coefficient values among the coatings investigated it is observed that the higher values were exhibited by the Tungsten Carbide at 5 and 10 $\mathrm{N}$, while Colmonoy 6 and Satellite 1 showed lower values of 0.60 and 0.68 , respectively. As for $\mathrm{Cr}_{2} \mathrm{O}_{3}$, both samples showed an irregular trend. Both curves exhibited a trend variation after the same test length.

In Figure 11 and Table 9 were compared the values of the friction coefficients obtained in this work with those reported in the literature [12]. As can be seen in this figure, the properties of In625 evaluate at $20^{\circ} \mathrm{C}$ and of the Tungsten Carbide (both at $5 \mathrm{~N}$ and at $10 \mathrm{~N}$ load) exhibit a higher friction coefficient compared to that exhibited by lowcarbon steel. Furthermore, it is observed that the
Table 9: Friction coefficient of different coatings.

\begin{tabular}{|l|l|}
\hline Coating Material & $\begin{array}{l}\text { Friction } \\
\text { coefficient }\end{array}$ \\
\hline Low-carbon steel & 0.58 \\
\hline In625 $20^{\circ} \mathrm{C}$ & 0.76 \\
\hline $\operatorname{In} 6251000^{\circ} \mathrm{C}$ & 0.54 \\
\hline $\operatorname{In} 625-\mathrm{Cr}_{2} \mathrm{O}_{3}-\mathrm{Ag} 20^{\circ} \mathrm{C}$ & 0.35 \\
\hline In625-Cr ${ }_{2} \mathrm{O}_{3}-\mathrm{Ag} 1000^{\circ} \mathrm{C}$ & 0.25 \\
\hline Tungsten Carbide $5 \mathrm{~N}$ & 0.87 \\
\hline Tungsten Carbide $10 \mathrm{~N}$ & 0.84 \\
\hline $\begin{array}{l}\text { CoNiCrAlY bond coat and Chromium } \\
\text { Oxide top coat }\end{array}$ & 0.39 \\
\hline
\end{tabular}

In625 friction coefficient decreases with increasing temperature reaching a value lower than that of the base low-carbon steel.

Figure 12 shows the wear rate average results of Stellite 1 , Colmonoy 6 and $\mathrm{Cr}_{2} \mathrm{O}_{3}$ coatings. Among all 


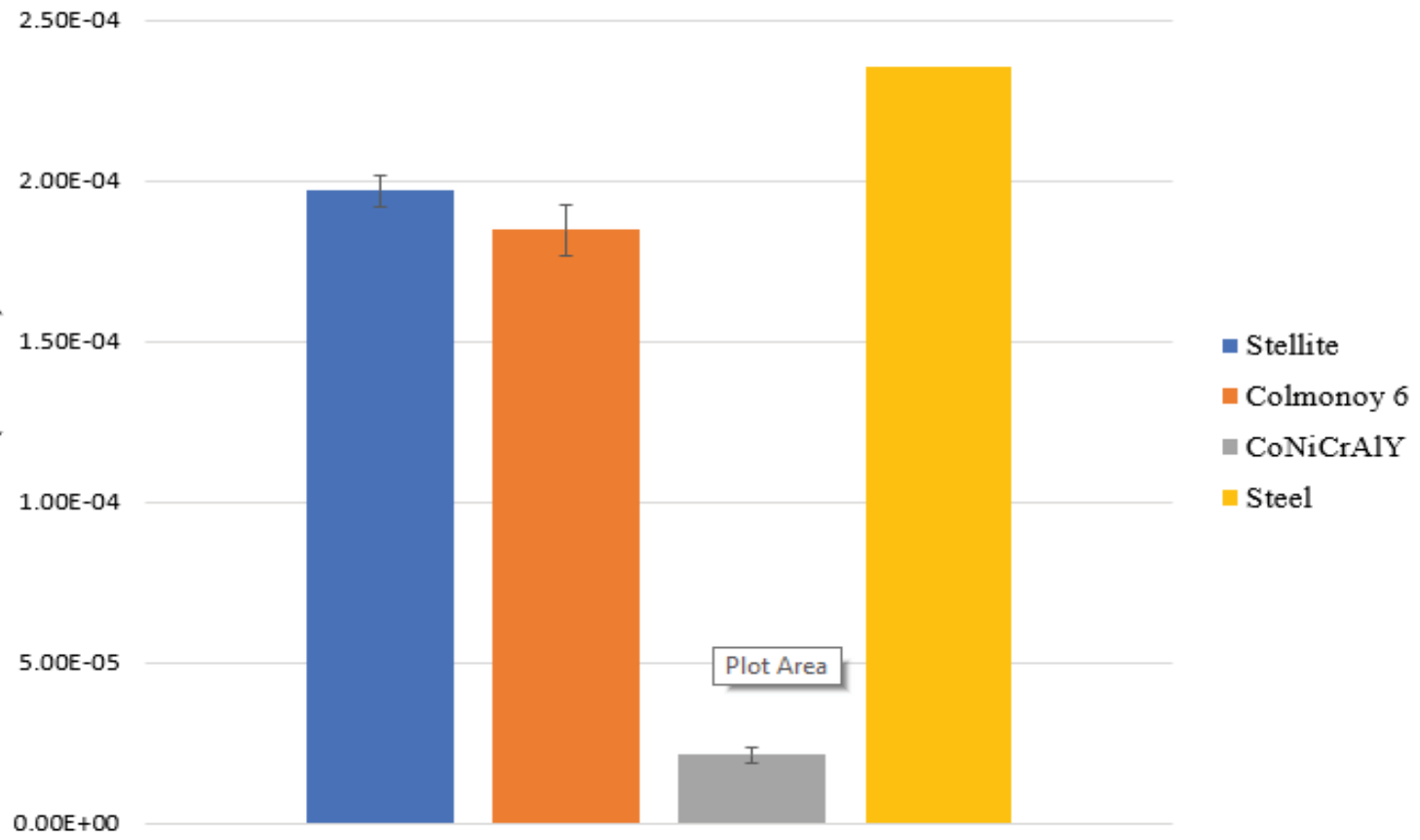

Figure 12: Wear rate average histograms of thermal spray coatings.

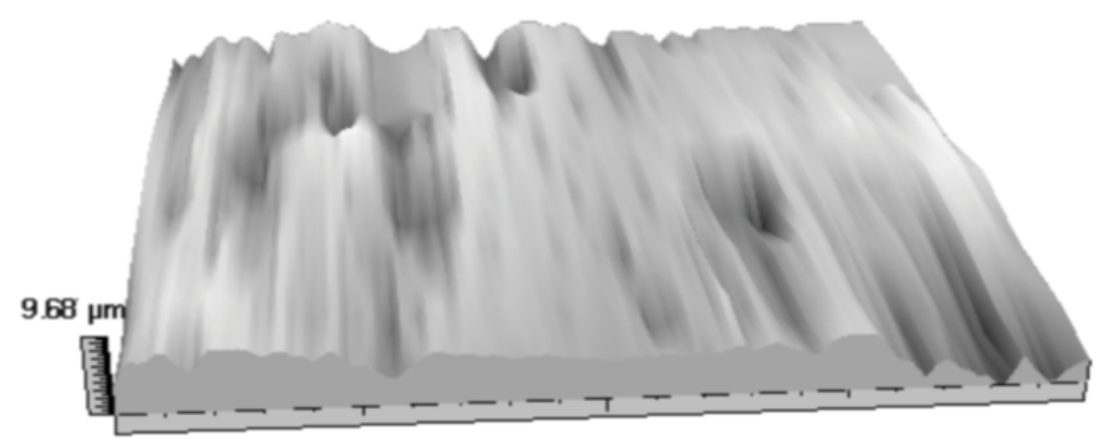

$2000 \mu \mathrm{m}$

Figure 13: Tri-dimensional profile of tungsten carbide coating wear track at $5 \mathrm{~N}$.

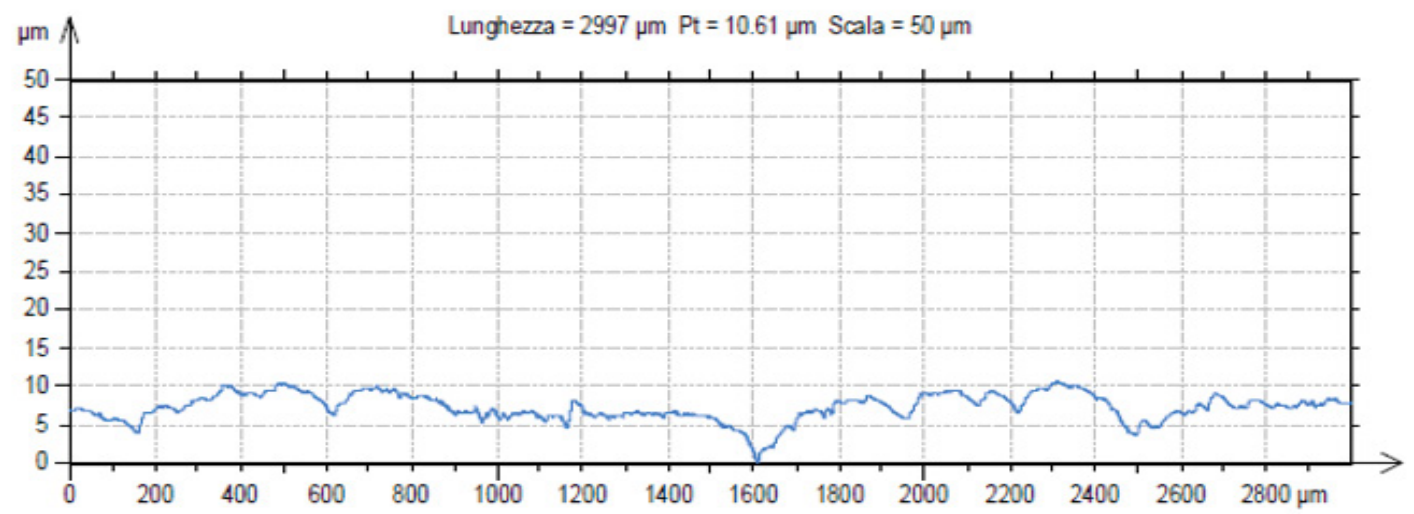

Figure 14: Bidimensional profile of tungsten carbide coating wear track at $5 \mathrm{~N}$. 
the other materials, Colmonoy 6 samples showed much higher wear resistance compared to Stellite 1 , while $\mathrm{Cr}_{2} \mathrm{O}_{3}$ exhibited a higher wear resistance.

The results exhibited by the Tungsten Carbide coating were not reported in this figure due to the impossibility to measure wear tracks in this case. The reason of the lack is due to the impossibility to measure wear tracks as reported in Figure 13, Figure 14, Figure 15 and Figure 16. In fact, tests carried out for Tungsten Carbide coatings at both tests ( 5 and $10 \mathrm{~N}$ ), the surfaces of the specimens were only flattened.

In Figure 17 and Table 10 were compared the values of the wear rate obtained in this work

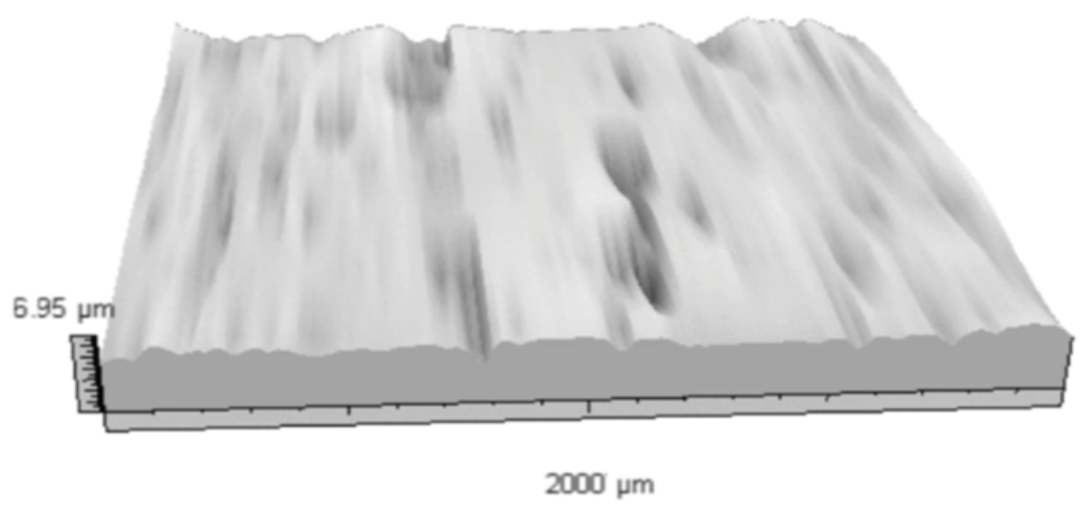

Figure 15: Tri-dimensional profile of tungsten carbide wear track at $10 \mathrm{~N}$.

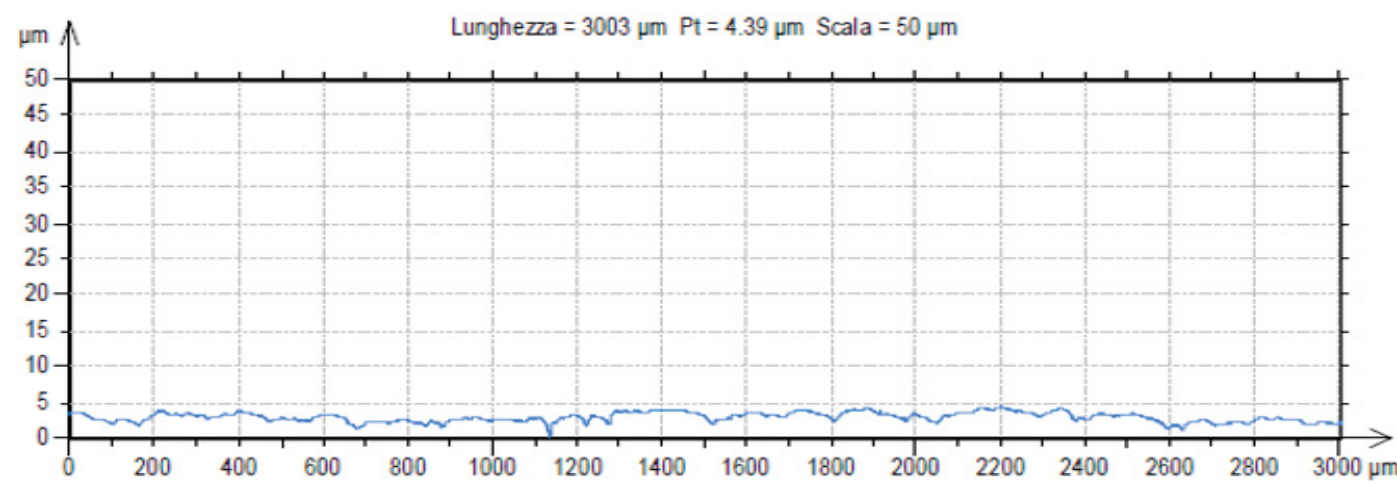

Figure 16: Bidimensional profile of tungsten carbide wear track at $10 \mathrm{~N}$.

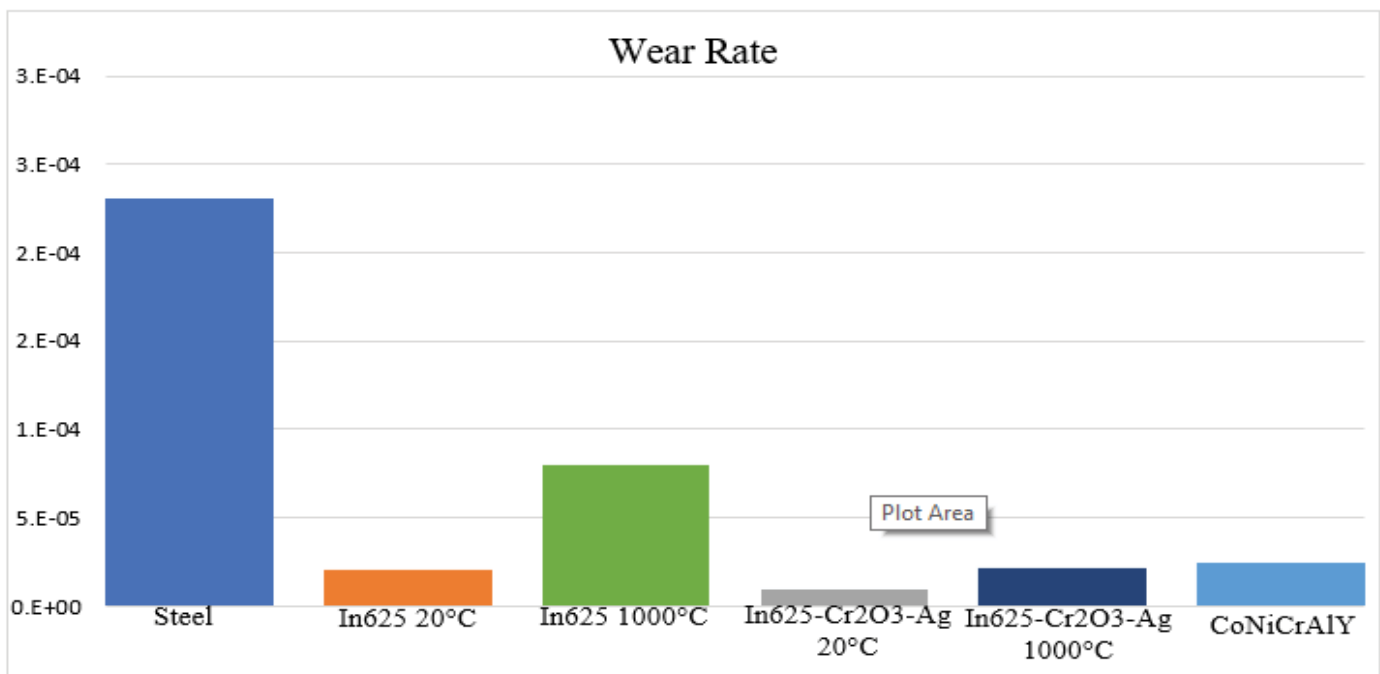

Figure 17: Wear rate value of different coatings. 
with those reported in Ref. 12. As a matter of fact, all coatings analysed exhibit a lower wear rate compared to that shown by the low-carbon steel substrate. In625- $\mathrm{Cr}_{2} \mathrm{O}_{3}-\mathrm{Ag}$ coating shows the lowest wear rate (at $20^{\circ} \mathrm{C}$ and at $1000{ }^{\circ} \mathrm{C}$ ). On the other hand, this coating presents the lower friction coefficient that makes braking less efficient. As reported above, in Figure 12 were not shown the wear rate of tungsten carbide.

Considering the friction coefficient and wear rate results at the same time it can be concluded that the Tungsten Carbide coating presents the better tribological properties compared to the other investigated coatings. In fact, it exhibits the higher friction coefficient and wear resistance.

\section{Thermal properties}

Since thermal conductivity and diffusivity are intrinsic properties of material, it is possible to calculate them by using literature data $[20,21]$. Figure 18 and Figure 19 show, respectively, the thermal conductivity and diffusivity histograms

Table 10: Wear rate values.

\begin{tabular}{|l|l|}
\hline Coating Material & $\begin{array}{l}\text { Wear Rate } \\
\left(\mathbf{m m}^{3} / \mathbf{N m}\right)\end{array}$ \\
\hline Low-carbon steel & 0.000231 \\
\hline In625 $20^{\circ} \mathrm{C}$ & 0.000021 \\
\hline $\operatorname{In} 6251000^{\circ} \mathrm{C}$ & 0.00008 \\
\hline In625- $\mathrm{Cr}_{2} \mathrm{O}_{3}-\mathrm{Ag} 20^{\circ} \mathrm{C}$ & 0.00001 \\
\hline In625-Cr $\mathrm{O}_{3}$-Ag $1000^{\circ} \mathrm{C}$ & 0.000022 \\
\hline Tungsten Carbide $5 \mathrm{~N}$ & $\mathrm{NA}$ \\
\hline Tungsten Carbide $10 \mathrm{~N}$ & $\mathrm{NA}$ \\
\hline $\begin{array}{l}\text { CoNiCrAlY bond coat and Chromium } \\
\text { Oxide top coat }\end{array}$ & 0.000025 \\
\hline
\end{tabular}

of the produced coatings, while in Table 11 were reported the relative data.

In the Ref. 12 were not reported the thermal properties of the coatings produced in this work, but it was possible to find the thermal properties of Inconel 625 from the data sheet provided by Sandvik, supplier of the powder used for the realization of the high pressure cold spray coating. As a matter of fact, all coatings analysed exhibit lower thermal properties compared to that shown by the low-carbon steel substrate, except for the tungsten carbide. In fact, as reported in Figure 16 and Figure 17 and in Table 10, considering the thermal conductivity and diffusivity results at the same time it can be concluded that the Tungsten Carbide coating presents the better thermal properties compared to the other investigated coatings. This means that coatings made in Tungsten Carbide exhibits a high capacity to propagate the thermal field even in non-stationary conditions without accumulating it into the braking rotor-stator interfaces, improving heat dissipation and avoiding the overheat of the friction surfaces with catastrophic consequences.

\section{Conclusion}

In this paper, different coatings for aircraft brake application produced with two thermal spray technologies were analysed. The ideal coating material for the best braking action should exhibit high tribological properties, specifically high friction coefficient and high wear resistance, high thermal properties, in particular high thermal conductivity and diffusivity, good adhesion to the substrate, a compact microstructures and low porosity inside the coating. In addition, it should be very light in

Table 11: Thermal properties values.

\begin{tabular}{|c|c|c|c|c|}
\hline & $\begin{array}{l}\text { Thermal Conductivity } \\
\text { (W/mK) }\end{array}$ & $\begin{array}{l}\text { Density } \\
\left(\mathrm{g} / \mathrm{cm}^{3}\right)\end{array}$ & $\begin{array}{l}\text { Specific Heat } \\
\left(\mathrm{J} / \mathrm{g}^{\circ} \mathrm{C}\right)\end{array}$ & $\begin{array}{l}\text { Thermal Diffusivity } \\
\left(\mathrm{m}^{2} / \mathrm{s}\right)\end{array}$ \\
\hline Low-carbon steel & 54 & 7.85 & 0.49 & $1.40 \cdot 10^{-5}$ \\
\hline $\ln -62521^{\circ} \mathrm{C}$ & 9.8 & 8.4 & 0.41 & $2.84 \cdot 10^{-6}$ \\
\hline In-625 $760^{\circ} \mathrm{C}$ & 20.8 & 8.4 & 0.59 & $4.20 \cdot 10^{-6}$ \\
\hline Tungsten Carbide & 110 & 15.63 & 0.3 & $2.34 \cdot 10^{-5}$ \\
\hline Stellite 1 & 14.85 & 8.69 & 0.423 & $4.04 \cdot 10^{-6}$ \\
\hline Colmonoy $621^{\circ} \mathrm{C}$ & 11.74 & 8.1 & 0.4857 & $2.98 \cdot 10^{-6}$ \\
\hline Colmonoy $6760^{\circ} \mathrm{C}$ & 25.1 & 8.1 & 0.62 & $4.50 \cdot 10^{-6}$ \\
\hline CoNiCrAlY $25^{\circ} \mathrm{C}$ & 5.5 & 7.992 & 0.473 & $1.45 \cdot 10^{-6}$ \\
\hline
\end{tabular}




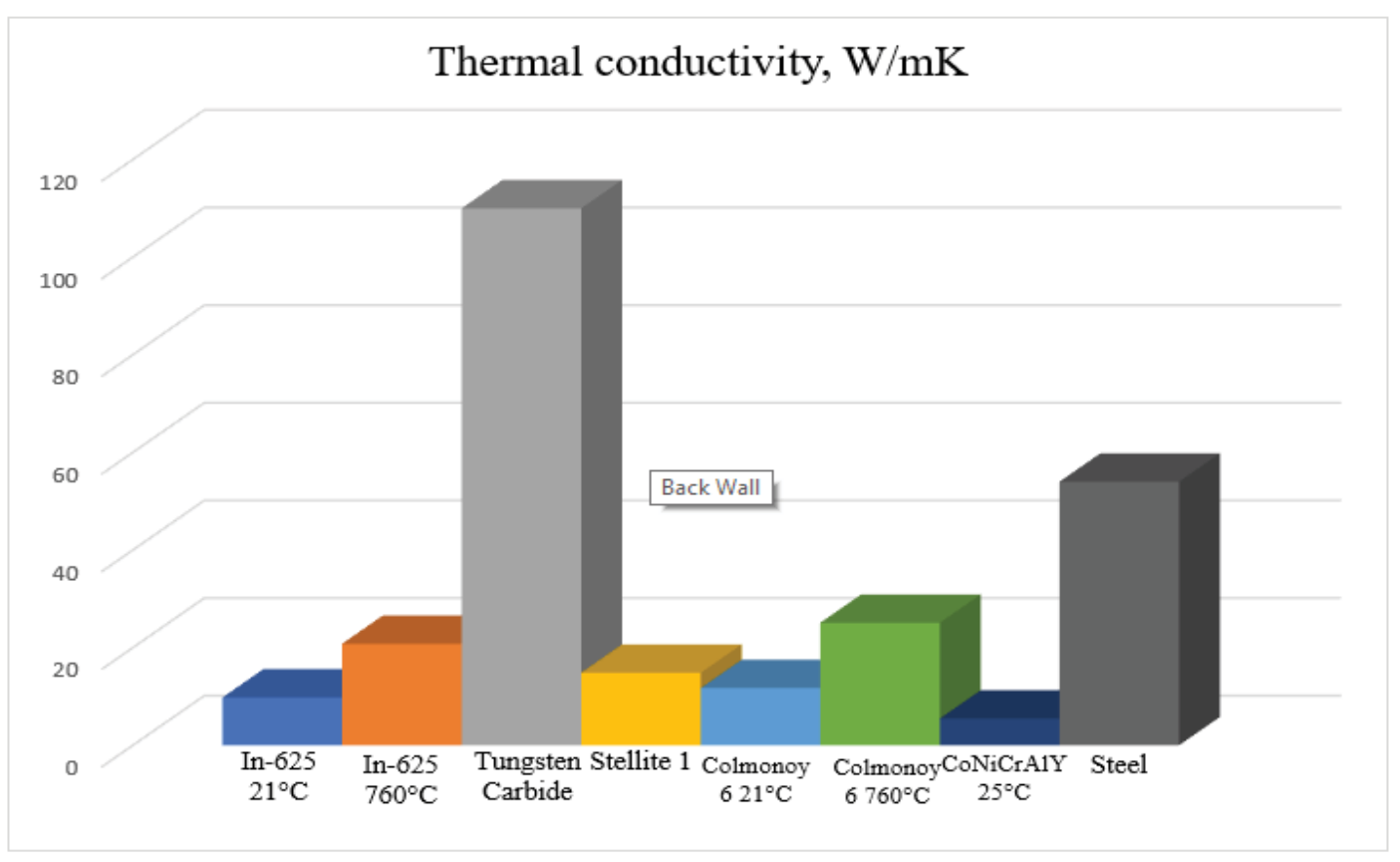

Figure 18: Thermal conductivity of analysed coatings.

\section{Thermal Diffusivity, $\mathrm{m}^{2} / \mathrm{s}$}

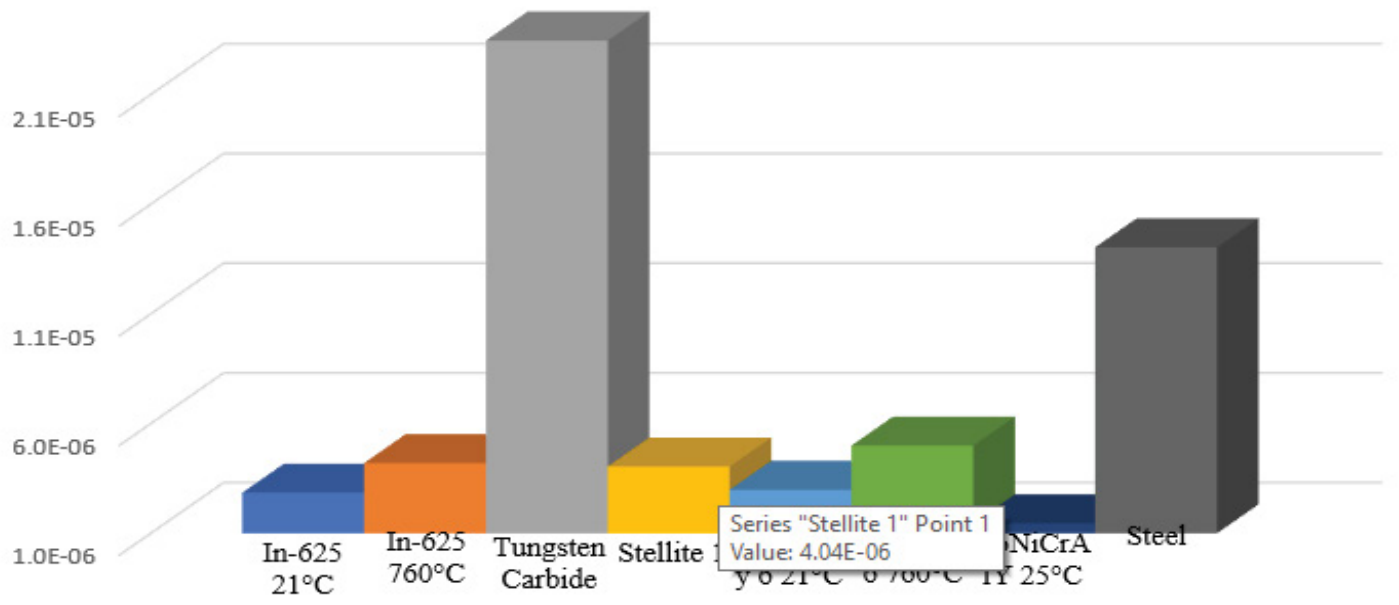

Figure 19: Thermal diffusivity of analysed coatings.

order to reduce the total weight of the vehicle, as well as design and production should be low cost. Results obtained in this investigation can be summarized as follows:

1. The HVOF sprayed specimens' structures present a light grey colour on the entire coated surface, while the Plasma sprayed one's exhibit a dark grey colour on the entire coated surface. The coatings present a very low level of porosity (less than 1\%), absence of un-melted particles, a very low present of oxides and no cracks. No interface separation and contamination between the different materials present into the coatings were observed. Similar hardness values were obtained for all the tested coatings.

2. All the coatings produced, except for $\mathrm{Cr}_{2} \mathrm{O}_{3^{\prime}}$ exhibit higher friction coefficient and wear resistance compared to the low-carbon steel substrate. Among all tungsten carbide shows the highest friction coefficient (0.84).

3. All the coatings show higher wear resistance compared to the low-carbon steel substrate. 
It is worth to mention that the results shown by the tungsten carbide coating were not reported due to the impossibility to measure the wear tracks at both the nominal loads employed ( 5 and $10 \mathrm{~N}$ ).

4. Scratch tests results showed a high adhesion of coatings on the low-carbon steel substrate. In fact, all the specimens exhibit high critical loads related to the crack initiation and the detachment of the coating. Also in this case, tungsten carbide coating presents the better adherence to low-carbon steel substrate. The results show a critical load at the beginning of cracks at about $10 \mathrm{~N}$ and a critical load of separation at $65 \mathrm{~N}$.

5. All analysed coatings exhibit lower thermal properties compared to low-carbon steel, except for the tungsten carbide. In fact, tungsten carbide coating exhibit high thermal conductivity (about $110 \mathrm{~W} / \mathrm{mK}$ ) and diffusivity (about $2.34 \cdot 10^{-5}$ ). This means that coatings made in tungsten carbide has high capacity in propagate the thermal field even in nonstationary conditions without accumulating it into the braking rotor-stator interfaces avoiding the overheat of the friction surfaces with catastrophic consequences.

6. A comparative analysis results with a literature paper [13] highlights that it is possible to produce via Thermal Spray Technologies different friction coatings with higher tribological, mechanical and thermal properties.

Carrying out a comparative analysis of the results obtained, it can be concluded that the tungsten carbide coating exhibits superior properties compared to the other investigated coatings. Therefore, a small tungsten carbide thickness $(0.5 \mathrm{~mm})$ can improve the braking action without greatly altering the brake weight. The application of this coating presents an additive cost, but thanks to its high properties, the braking action improves, and the brake wear is reduced, and its life in-service is improved.

In the light of these results, for the future work, analysis about the variation of friction coefficient and wear rate of the coting materials reported as a function of temperature can be performed. Furthermore, another fundamental aspect may concern the stability of friction coefficient (dynamic and or static) and, also, the wear rate stability of the friction coatings analysed.

\section{Acknowledgements}

The authors acknowledge the financial support of Clean Sky 2 Joint Undertaking (CS2JU), EU Horizon 2020 research and innovation program, under project no. 821079, E-Brake.

\section{References}

1. Shruti N, Shreya N (2014) Aircraft braking system. IJRMET, 4.

2. Marshall BP, Ting LH (1972) Consideration of materials for aircraft brakes. NASA CR-121116.

3. Shangwu $F$, Chuan $\mathrm{Y}$, Liuyang $\mathrm{H}$, Yong $\mathrm{D}$, Walter $\mathrm{K}$, et al. (2016) Progress of ceramic matric composites brake materials for aircraft application. IPME RAMS 44: 313-325.

4. Shangwu F, Litong $Z$, Yongdong $X$, Laifei $C$, Guanglai $T$, et al. (2008) Microstructure and tribological properties of advanced carbon/silicon carbide aircraft brake materials. Composite Science and Tecnologiy 68: 3002-3009.

5. Maleque MA, Abdullahi U (2013) Materials and processing route for aircraft brake system. International Journal of Mechanical and Materials Engineering 8: 14-20.

6. Awasthi S, Wood JL (1988) Carbon/carbon composite materials for aircraft brakes. Ceramic Engineering and Science Proceedings.

7. Guan QF, Li GY, Wang HY, An J (2004) Friction-wear characteristics of carbon fiber reinforced friction material. Journal of Materials Science 39: 641-643.

8. Dongma $E$, Wenzelburger $M$, Gadow R (2008) Analysis and optimization of the HVOF process by combined experimental and numerical approaches. Surface \& Coatings Technology 202: 4470-4478.

9. Koutský J (2004) High velocity oxy-fuel spraying. Journal of Materials Processing Technology 157-158: 557-560.

10. Pawlowsky $L$ (1995) The science and engineering of thermal spray coatings. Wiley.

11.Sidhu TS, Prakash S, Agrawal RD (2005) State of the art of HVOF coating investigations. Marine Technology Society Journal 39: 53-64.

12.Jie C, Hui S, Guang L, Bing M, Yulong A, et al. (2019) Cold spraying: A new alternative preparation method for nickel-based high-temperature solid-lubrication coating. Journal of Thermal Spray Technology, 29. 
13.Prodotti Linea Gamma Tecnica GT.

14.Elwood Haynes (1907) Metal alloy. US Patent no. 873

\section{LSN diffusion.}

16. Lincotek surface solutions.

17. Thermal spray powders. Praxair Surface Technologies.

18.Abdullah CK, Yasin O, Kadir MD (2020) Comparison of microstructure and oxidation behavior of CoNiCrAlY coatings produced by APS, SSAPS, D-gun, HVOF and CGDS techniques. Vacuum 180: 109609.
19.Byron BR, Warren ES, Edwin NL (1960) Transport phenomena. John Wiley \& Sons, Inc, 243-265.

20.Farwick DG, Johnson RN (1980) Thermophysical properties of selected wear-resistant alloys. Hanford Engineering Development Lab, Richland, WA.

21.Pierson HO (1996) Handbook of refractory carbides and nitrides properties, characteristics, processing and applications. Noyes Publications, New Jersey, 100-116. 